\title{
THE REPORTED INCIDENCE OF GLANDULAR FEVER AN ANALYSIS OF A REPORT OF THE PUBLIC HEALTH LABORATORY SERVICE BY
}

\author{
K. W. NEWELL \\ From the Epidemiological Research Laboratory, Colindale, London
}

(RECEIVED FOR PUBLICATION SEPTEMBER 15, 1956)

Glandular fever is not, as far as is known, notifiable in any country, and most published epidemiological studies record observations on special groups-soldiers, sailors, students, nurses, or hospital admissions. There is therefore no comprehensive information on the age, sex, seasonal, or occupational distribution of the disease. In recent years pathologists in public health and hospital laboratories in England and Wales have been voluntarily making weekly reports on cases of infectious disease diagnosed in their laboratories to the Director of the Public Health Laboratory Service. The list of diseases for which reports are made includes glandular fever, and in 1955 pathologists were asked to give for each case diagnosed the age, sex, and occupation of the patient. Though about $98 \%$ of the hospital and public health laboratories in England and Wales take part in the reporting scheme, it does not necessarily follow that every laboratory invariably reports cases of glandular fever ; there is evidence that some laboratories seldom report cases, and no claim is therefore made that this report gives the true incidence of laboratory diagnosed cases of the disease.

In a preliminary study in 1954 efforts were made to obtain detailed information on the titres obtained in the Paul-Bunnell test and on whether or not absorption tests were made, but the interpretation of results from so many different pathologists was difficult, and in the main study in 1955 pathologists were only asked to record if they based their diagnosis on the results of serological tests, or on haematological examinations, or both. When titres were given, a positive serological test was considered to be one with a heterophile antibody titre greater than 1 in 64 which did not decrease by more than one dilution after absorption with guinea-pig kidney, and which decreased by more than two dilutions after absorption with ox cells.

\section{Number of Cases}

In 1955 pathologists reported 1,861 cases of which 1,769 were diagnosed serologically, alone or in conjunction with blood and clinical examinations, and 92 were similar to glandular fever clinically and haematologically, but had negative serological findings. The analysis deals only with the 1,769 serologically confirmed cases in order to make the group as homogeneous as possible. None of the cases occurred in outbreaks. Sometimes cases did appear to be concentrated in one district over a short period, but no obvious connexions between the cases were found. No detailed field study of the possibility of association between the cases was made.

\section{Age}

The age distribution of cases is given in Table $I$. In 96 cases the age, and in 80 cases the sex, was not stated. Most, $61 \%$ of the total reported, occurred in the 15-24 age group, $18 \%$ were in children under 15 years of age, and $21 \%$ were in persons 25 years old or more. The rates (cases per 100,000$)$ for the populations in these three age groups were: $0-14$ years $3.0,15-24$ years 17.4 , and 25 years and more 1.1 (using populations from the $1 \%$ sample tables from the Census 1951, Part 1 ).

\section{Sex}

Half the cases at all ages were in males and half in females (Table I), but there were differences in the proportions of the sexes in different age groups.

TABLE I

AGE AND SEX DISTRIBUTION OF CASES OF GLANDULAR FEVER, 1955

\begin{tabular}{c|c|c|c}
\hline $\begin{array}{c}\text { Age } \\
\text { (Years) }\end{array}$ & Males & Females & $\begin{array}{c}\text { Male/Female } \\
\text { Ratio }\end{array}$ \\
\cline { 1 - 2 } $0-$ & 17 & 15 & $1 \cdot 13$ \\
$5-$ & 89 & 73 & 1.22 \\
$10-$ & 60 & 39 & 1.54 \\
$15-$ & 170 & 264 & 0.65 \\
$20-$ & 296 & 246 & 1.20 \\
$25-$ & 89 & 68 & $1 \cdot 31$ \\
$30-$ & 46 & 56 & 0.82 \\
$35+$ & 32 & 33 & 0.97 \\
\hline Not stated & 61 & 35 & 1.73 \\
\hline Total * & 860 & 829 & 1.03 \\
\hline
\end{tabular}

Eighty cases in which the sex was not given are excluded from this table. 
Under 15 years, $56 \%$ of cases, when the age was given, were in males, but between 15 and 19 years only $39 \%$ of cases were in males ; from 20 years and upwards $53 \%$ were in males. The lower proportion of cases in males between 15 and 19 years was also seen in the preliminary study in 1954.

\section{Season}

The seasonal distribution of cases in persons under 15 years and in persons 15 years and over is shown in Fig. 1. In adults there was an increased incidence in the summer and autumn compared with the winter and spring, and there was perhaps a slight rise in March. In children there appeared to be no seasonal variation in incidence.

\section{Regional Distribution}

Cases were allocated to standard regions as defined by the Registrar-General, according to the situation of the reporting laboratory, not the patient's home address, and were related to the total population of the appropriate region (Table II). The reported incidence increased progressively from about 2 per 100,000 in the north to about 6 per 100,000 in the south. The rates for adults and children were proportionally the same in all regions. One cannot be sure that the
TABLE II

GEOGRAPHICAL DISTRIBUTION OF CASES OF GLANDULAR FEVER, 1955

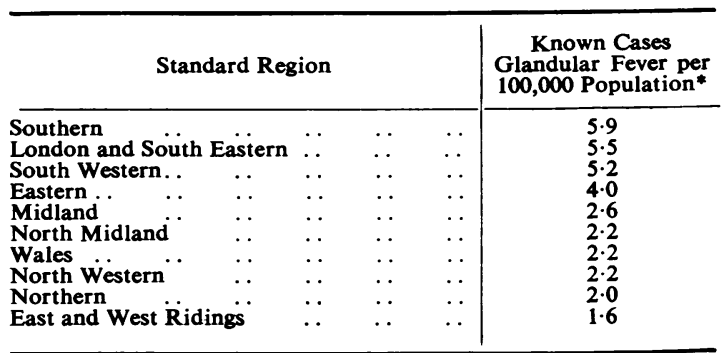

* Populations were estimated populations given in the Statistical Review (1954).

gradient in the reported incidence is an accurate indication of that of the true incidence. The difference might be due to the different availability of laboratory services in the north compared with the south, or to a difference in the frequency with which clinicians in the two areas use the services available. So far as the Public Health Laboratory Service laboratories are concerned, more specimens are examined per 100,000 persons in the north than in the south, but most glandular fever cases are reported from hospitals for which information on the number of specimens examined is not available.

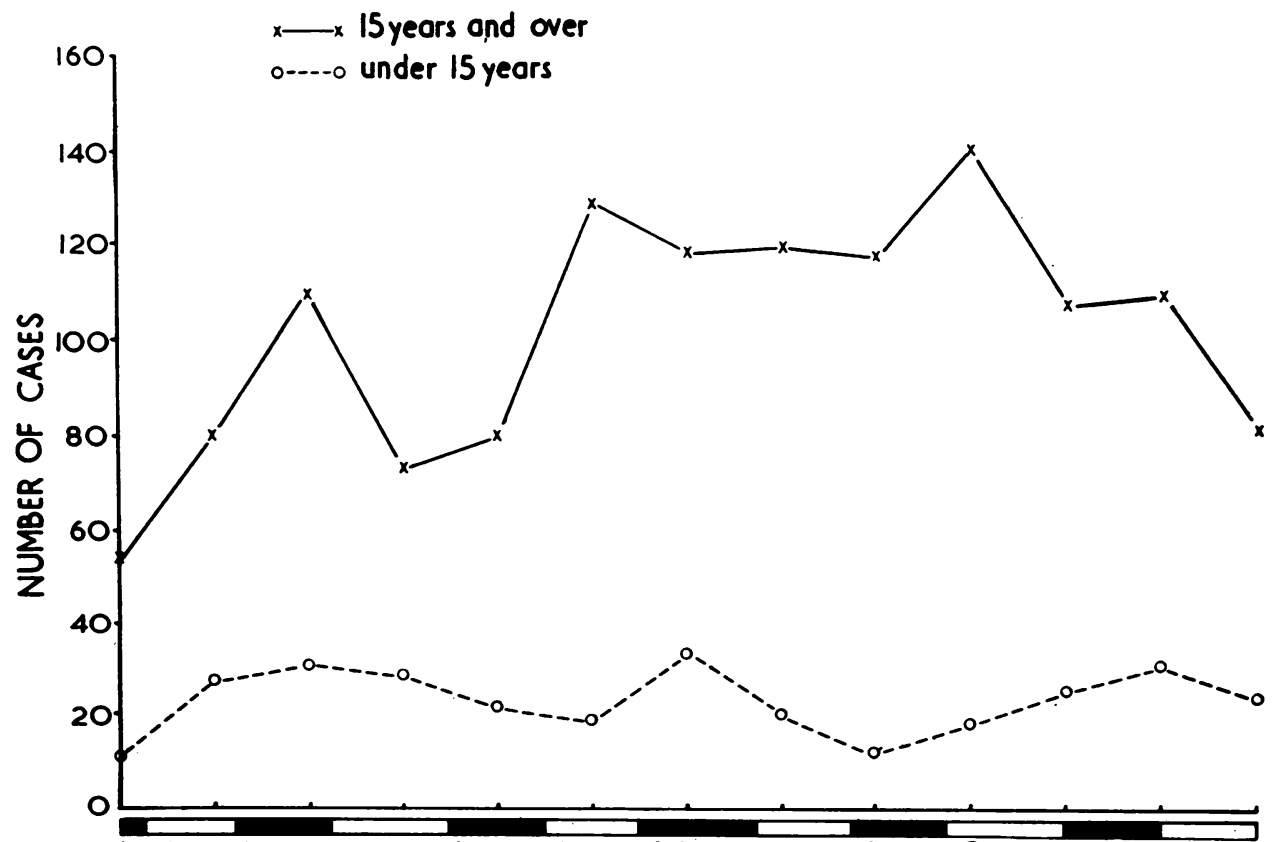

JAN. FEB. MAR. APR. MAY JUNE JULY AUG. SEPT. OCT. NOV. DEC.

FIG. 1 


\section{Occupation}

The occupation was given for 748 cases between the ages of 16 and 34 years $(62 \%$ of those reported between these ages) and rates per 100,000 have been calculated for some broad occupational groups (Table III). It is probable that the occupation was more often given for nurses and members of the Services than for other occupations. In both sexes the gradient from the highest

TABLE III

OCCUPATIONS OF 748 PATIENTS BETWEEN 16 AND 34 YEARS WITH GLANDULAR FEVER, 1955

\begin{tabular}{|c|c|c|}
\hline Occupation & $\begin{array}{c}\text { Number of } \\
\text { Patients }\end{array}$ & $\begin{array}{l}\text { Rate per } \\
100,000^{*}\end{array}$ \\
\hline 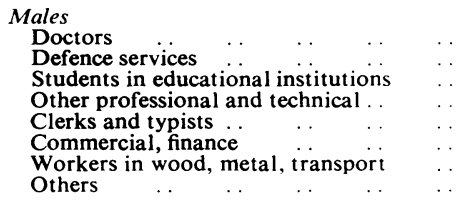 & $\begin{array}{r}7 \\
135 \\
51 \\
32 \\
27 \\
14 \\
47 \\
60\end{array}$ & $\begin{array}{r}59.8 \\
26.9 \\
26.0 \\
9.5 \\
6.6 \\
3.6 \\
2.7\end{array}$ \\
\hline All males.. & 373 & \\
\hline 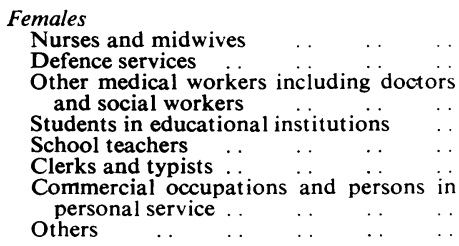 & $\begin{array}{r}88 \\
9 \\
26 \\
28 \\
11 \\
106 \\
47 \\
60\end{array}$ & $\begin{array}{l}40.5 \\
17.8 \\
13.5 \\
10 \cdot 8\end{array}$ \\
\hline All females & 375 & \\
\hline
\end{tabular}

* Populations of Great Britain by occupation were taken from the $1 \%$ sample tables census, 1951 . to the lowest appears to coincide with the acces- $\overrightarrow{\vec{F}}$ sibility to diagnostic services. Separate rates calculated for ages 16-19 years, 20-24 years, and 25-34 years for the Defence services, nurses, $\frac{}{\omega}$ students, and clerks and typists showed that the $\vec{\nabla}$ rates between 20 and 24 years were more than twice as high as those in other age groups. It might be expected that in certain occupations $\overrightarrow{0}$ associated with communal living, e.g., soldiers or nurses, there might be greater chances of becoming $\vec{\omega}$ ill with a disease soon after joining the group. This does not appear to occur.

\section{Summary and Conclusions}

Reports made through public health and $\stackrel{N}{\circ}$ hospital laboratories in 1955 of 1,769 serologically 음 confirmed cases of glandular fever were analysed. $\rightarrow$ Fifty-six per cent. of cases in children under 15 Th years of age, but only $39 \%$ of cases in persons between 15 and 19 years, were in males. More adult cases occurred in the summer, but cases under 15 years occurred evenly throughout the year. $\overrightarrow{0}$ Attack rates were apparently higher in the south of $V$ England than in the north. The occupations of $62 \%$ of patients between 16 and 34 years of age were recorded. It appeared probable that occu- 금 pational differences could be explained by the accessibility of diagnostic facilities. The age $\mathbb{\otimes}$ group of highest incidence appeared to be similar in a number of different occupations.

This epidemiological study was not continued in 1956 , as it was unlikely to provide additional information of value. 